\title{
Inglês como Língua Franca (ILF) e o ensino-aprendizagem de língua inglesa em tempos de ensino remoto: um relato de caso aplicado ao ensino fundamental I
}

\author{
English as a Lingua Franca (ELF) and the teaching-learning of the English \\ language in a municipal elementary school in pandemic times: a report on \\ English teaching-learning practices
}

\author{
Jane Helen Gomes de Lima \\ Doutoranda em Inglês \\ Universidade Federal de Santa Catarina - UFSC \\ Florianópolis, SC - Brasil \\ Secretaria Municipal de Educação - SMED. \\ Forquilhinha, SC - Brasil \\ janehelenglima@gmail.com \\ iD Gislane Savio \\ Especialista em Alfabetização e Letramento \\ Secretaria Municipal de Educação - SMED. \\ Forquilhinha, SC - Brasil. \\ gislanesavio@gmail.com \\ D Graziela Pavei Peruch Rosso \\ Doutora em Educação \\ Secretaria Municipal de Educação - SMED. \\ Forquilhinha, SC - Brasil \\ peruchgraziela@gmail.com
}

\begin{abstract}
Resumo: $\mathrm{O}$ ensino-aprendizagem da língua inglesa na educação básica passou por mudanças significativas em seu foco em meados de 2017, a partir das discussões propostas pela Base Nacional Comum Curricular (BNCC). Antes, norteado pelos Parâmetros Curriculares Nacionais (PCNs), o inglês era tratado como língua estrangeira (ILE). Agora, com as novas diretrizes curriculares nacionais, ele aparece como língua franca (ILF). O objetivo deste relato de experiência é apresentar a materialização do conceito de ILF em aulas virtuais de uma escola municipal de ensino fundamental I do extremo sul catarinense. Por meio da descrição e da análise de duas práticas de ensino-aprendizagem propostas durante o ensino remoto, discutimos como é possível levar a cabo a proposta do ILF numa perspectiva que busca descentralizar o falante nativo de inglês, expor as crianças aos diferentes tipos de ingleses, focar em suas competências comunicativas e incentivá-las, acima de tudo, a se experimentarem como falantes legítimas deste idioma.
\end{abstract}

Palavras-chave: Ensino-aprendizagem. Ensino remoto. Inglês como Língua Franca. Relato de experiência.

\begin{abstract}
The teaching-learning of the English language in basic education underwent significant changes in its focus in mid-2017, from the discussions proposed by the Brazilian Common Core Curriculum (BNCC). Before, guided by the National Curriculum Parameters (PCNs), English was treated as a foreign language (EFL). Now, with the new national curriculum guidelines, it appears as a lingua franca (ELF). The purpose of this experience report is to present the materialization of the ELF concept in virtual classes at a municipal elementary school in the extreme south of Santa Catarina. Through the description and analysis of two teaching-learning practices proposed during remote teaching, we discuss how it is possible to carry out the ELF proposal in a perspective that seeks to decentralize the native English speaker, exposing children to different types of English, focus on their communicative skills and encourage them, above all, to experience themselves as legitimate English speakers.
\end{abstract}

Keywords: Teaching-learning. Remote teaching. English as a Lingua Franca. Experience report. 
LIMA, Jane Helen Gomes de; SAVIO, Gislane; ROSSO, Graziela Pavei Peruch. Inglês como Língua Franca (ILF) e o ensino-aprendizagem de língua inglesa em tempos de ensino remoto: um relato de caso aplicado ao ensino fundamental I

\section{PCNs, BNCC, ILE, ILF e o ensino-aprendizagem de língua inglesa na educação básica}

Antes tratado como língua estrangeira pelos Parâmetros Curriculares Nacionais (PCNs), de 1998, o ensino-aprendizagem da língua inglesa na educação básica passou por mudanças significativas a partir das discussões propostas pela Base Nacional Comum Curricular (BNCC), de 2017, trazendo consigo o conceito de Inglês como Lingua Franca (ILF). Destarte, o que parece ter sido apenas uma simples alteração de nomenclatura apresentou consideráveis mudanças no modo como se efetiva o desenvolvimento desta língua, demandando dos professores da área um conhecimento mais acurado não apenas do conceito, mas de seu olhar pedagógico para o componente curricular e o repensar de suas formas de ensinar.

Enxergar o inglês como língua estrangeira (ILE) é, primeiramente, colocar o falante que tem este idioma como sua língua materna (L1) como falante modelo e, ainda como objetivo a ser alcançado no processo de ensino-aprendizagem. Por isso, o papel do professor e do aluno na escola seria, respectivamente, apenas ensinar e aprender um inglês que se conforme com o nativo padrão (conhecido como Standard English), normalmente assumido apenas nos modelos britânico ou americano, assumindo a língua inglesa o papel de língua estrangeira (não pertencente/alheia) para os aprendentes. Inicialmente, isso pode não causar estranhamento. Porém, ensinar na perspectiva do ILE também significa dizer que tanto o professor quanto o aluno se constituirão como falantes ilegítimos desta língua, pois sempre terão uma interlíngua, nunca alcançando o ideal de falar como um nativo. Em contrapartida, reconhecer o Inglês como Lingua Franca (ILF) nos permite entender que falantes do inglês fazem uso dele para poder se comunicar com pessoas que também falam esta língua (nativos ou não), não aprendendo apenas para reproduzi-lo. Nesse movimento, considerar o ILF como diretriz que norteia o processo de ensino-aprendizagem invita a desenvolver nos aprendentes uma comunicação de sucesso na vida real, dependendo mais da vontade dos interlocutores de negociar sentidos e significações para que, assim, possam se fazer compreensíveis uns para com os outros, sem terem que necessariamente se preocupar com os usos e a aderência às formas da chamada gramática padrão (CANAGARAJAH, 2007; GIMENEZ et al., 2015; JENKINS, 2012, 2015; JORDÃO, 2014; JORDÃO; MARQUES, 2018).

Mudar nem sempre é um processo fácil, principalmente quando a transformação envolve um paradigma conceitual que impacta diretamente nos modos de ser e fazer a educação em determinado contexto. Isso exige do professorado não apenas uma nova compreensão sobre a realidade, mas uma mudança de habitus pedagógico" para que o "novo" seja implementado. As alterações curriculares acerca do ensino da língua inglesa não fogem a essa regra. Alguns estudos, 
LIMA, Jane Helen Gomes de; SAVIO, Gislane; ROSSO, Graziela Pavei Peruch. Inglês como Língua Franca (ILF) e o ensino-aprendizagem de língua inglesa em tempos de ensino remoto: um relato de caso aplicado ao ensino fundamental I

inclusive, apontam para as dificuldades que os docentes (e também futuros professores) apresentam para articular em suas práticas os construtos do ILF (EL KADRI; GIMENEZ, 2013; SIQUEIRA; SOUZA, 2014).

É importante frisar que o fazer docente não é algo trivial, pois o professor está a todo momento "conceituando, construindo explicações e respondendo a interações sociais e sentidos compartilhados entre professores, alunos, pais, administração, tanto dentro quanto fora de sala de aula"2 (JOHNSON, 1999, p. 1, tradução nossa). Considera-se, portanto, que o professor de inglês precisa constantemente articular o seu objeto de conhecimento - que é a língua inglesa - e as ferramentas pedagógicas adequadas às mais diversas situações que vivencia. Articulação essa que deve sempre levar em conta as especificidades de seus alunos e as demandas de sua escola. Nesse sentido, a proposta deste artigo é relatar como foi materializado o conceito de Inglês como Lingua Franca no processo de ensino-aprendizagem de língua inglesa de uma escola municipal de ensino fundamental I do extremo sul catarinense, tendo por referência duas aulas remotas que ocorreram entre os meses de abril e julho de 2020 , envolvendo 14 turmas, do $1^{\circ}$ ao $5^{\circ}$ ano, de uma mesma professora.

\section{Escola de Educação Básica Professor Jakob Arns: educando em tempos de pandemia}

A Escola de Educação Básica Professor Jakob Arns, instituição-alvo da prática deste estudo, está localizada em Forquilhinha/SC e faz parte da rede de ensino deste município. Atualmente, possui 370 alunos matriculados entre a pré-escola e o $5^{\circ}$ ano do ensino fundamental I, nos períodos matutino e vespertino, sendo duas turmas de pré-escolar II ( 5 anos), três de $1^{\circ}$ ano, três de $2^{\circ}$ ano, três de $3^{\circ}$ ano, três de $4^{\circ}$ ano e duas de $5^{\circ}$ ano. A escola conta com 31 colaboradores em seu quadro funcional, sendo 21 educadores e, entre eles, uma professora de língua inglesa ${ }^{3}$ que atende a todas as turmas de ensino fundamental I, numa rotina de uma hora-aula semanal por grupo.

Com a necessidade de manter a oferta do ensino no período de quarentena, a Secretaria Municipal de Educação implantou a modalidade remota a partir do mês de abril do corrente ano. Nesse movimento, e para cumprir com as exigências do "novo" formato de se fazer chegar a educação às crianças da educação infantil e do ensino fundamental I, a rede municipal de Forquilhinha adotou como ferramenta principal de acesso às aulas a plataforma virtual Mazk ${ }^{4}$. Como um "tutor inteligente para ensino e aprendizagem de diversos temas" (O QUE É..., 2020, p. 1) desenvolvido pelo Laboratório de Tecnologias Computacionais (LabTeC) da Universidade Federal de Santa Catarina (UFSC - Campus Araranguá), o Mazk já havia sido apresentado aos 


\section{Dialogia}

LIMA, Jane Helen Gomes de; SAVIO, Gislane; ROSSO, Graziela Pavei Peruch. Inglês como Língua Franca (ILF) e o ensino-aprendizagem de língua inglesa em tempos de ensino remoto: um relato de caso aplicado ao ensino fundamental I

professores municipais em 2019, por meio de capacitação específica para uso do sistema. À época, a proposta visava disponibilizar ao corpo docente uma alternativa digital que complementasse os trabalhos realizados em sala de aula ${ }^{5}$. Apesar disso, poucos foram aqueles que aderiram ao instrumento, permanecendo seu uso, em grande parcela, restrito à atividade desenvolvida no próprio treinamento e a um simulado-diagnóstico organizado pela rede municipal para os alunos do $3^{\circ}$ ao $5^{\circ}$ ano do ensino fundamental. Iniciada a pandemia, nova capacitação foi realizada para que, desta vez, a ferramenta pudesse ser utilizada como meio principal de ensino.

Tratando-se das aulas, observa-se que cada professor tem um código individual, por meio do qual acessa o ambiente virtual. Cada lição é elaborada individualmente na forma de explanação, na qual podem ser inseridos — além do conteúdo teórico — vídeos, imagens, tabelas e até mesmo exemplos para facilitar a aprendizagem dos objetos de conhecimento trabalhados. Somado a isso, para fixar o conteúdo, a plataforma possibilita a elaboração de questionários objetivos e descritivos, que podem ser anexados à exposição de cada tema, formando o que o sistema denomina material. Depois de organizado esse material, o educador faz sua inclusão em uma sala, gerando, assim, um código que permite ao aluno se conectar ao conteúdo (Figura 1).

Figura 1 - Disposição das salas elaboradas pelo professor na plataforma Mazk e seus respectivos códigos

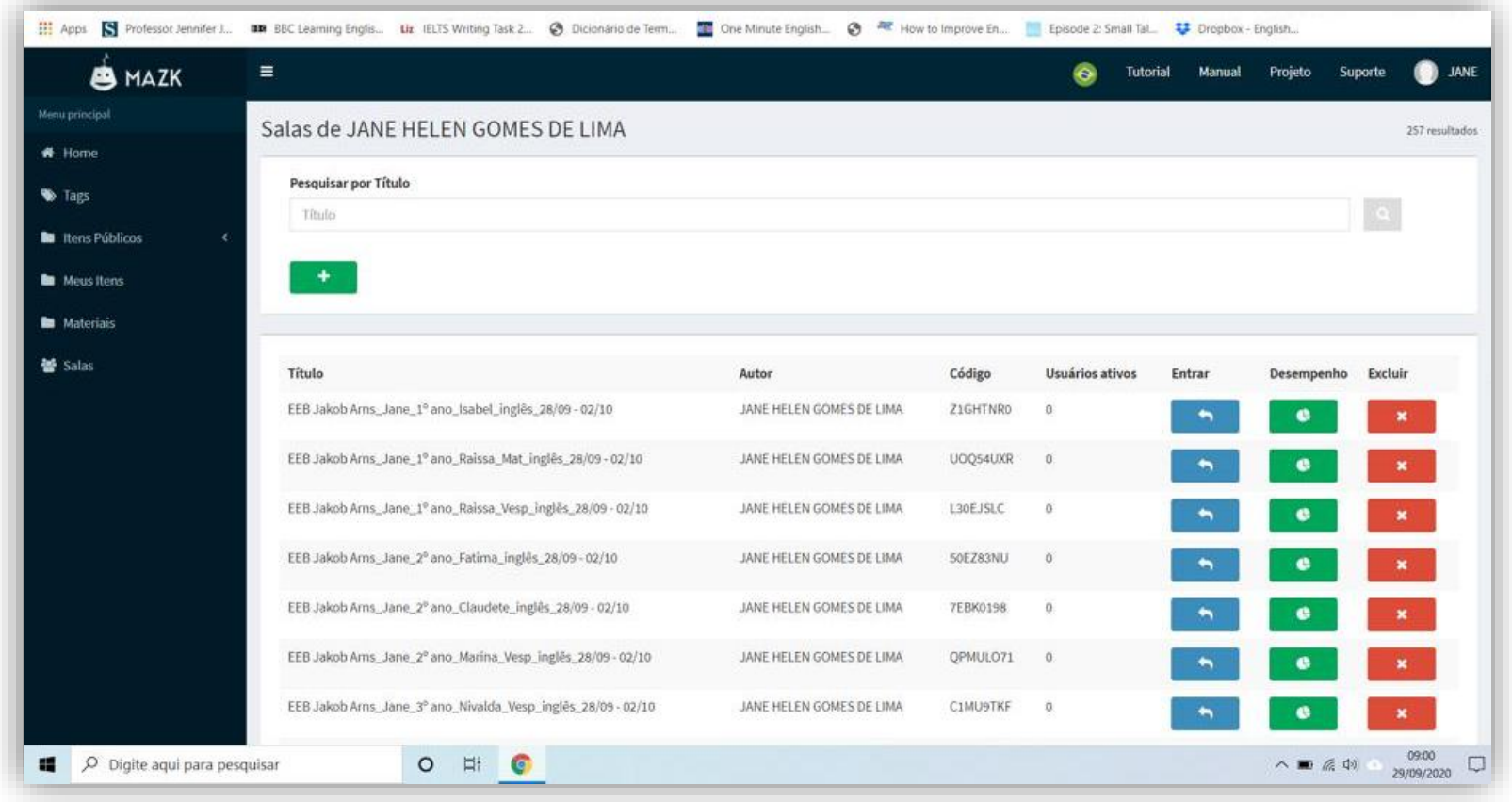

Fonte: Login pessoal da professora Jane Helen Gomes de Lima.

Tal qual o professor, o aluno também possui seu próprio login e senha de acesso à plataforma, cujo cadastro foi realizado pela coordenação pedagógica de cada instituição municipal de ensino e encaminhado às famílias pelo Whats $A p p$. Contudo, mais do que possibilitar a entrada 
LIMA, Jane Helen Gomes de; SAVIO, Gislane; ROSSO, Graziela Pavei Peruch. Inglês como Língua Franca (ILF) e o ensino-aprendizagem de língua inglesa em tempos de ensino remoto: um relato de caso aplicado ao ensino fundamental I

no ambiente virtual, a identificação eletrônica do aluno permite ao educador verificar a frequência nas aulas, além de corrigir atividades e avaliações de cada aluno.

\section{Falando sobre food com um viés de Inglês como Língua Franca (ILF)}

A língua inglesa passou a ser ofertada aos alunos das escolas municipais de Forquilhinha em 2016, do $1^{\circ}$ ano ao $5^{\circ}$ ano do ensino fundamental I, seguindo a proposta curricular da Rede municipal de ensino da cidade em vigência na época ${ }^{6}$. Nas escolas desta rede, todos os alunos do $1^{\mathrm{o}}$ ao $5^{\circ}$ ano têm uma aula de inglês por semana, com duração de 44 minutos. Com a preocupação de proporcionar um melhor aproveitamento do tempo de aula, o município decidiu adquirir livros de inglês para todos os estudantes. Os livros deste componente curricular são os únicos adquiridos por meio de licitação, já que os materiais integrantes do Programa Nacional do Livro e do Material Didático (PNLD, 2020) para o componente língua inglesa, seguindo as orientações da BNCC, só estão disponíveis para o $6^{\circ}$ ano em diante.

A coleção de livros adquirida para o componente inglês no ano de 2020 foi a "Brincando com Inglês" (CURTO JÚNIOR; SANSON; GUIMARÃES, 2016), sendo disponibilizada para todas as turmas do ensino fundamental I como ferramenta principal de instrução. O planejamento anual para o componente curricular língua inglesa na escola Jakob Arns foi desenvolvido a partir da proposta curricular do município ${ }^{7}$ (FORQUILHINHA, 2020), dos objetos de conhecimento especificados pelas cinco edições da coleção Brincando com Inglês e de atividades extras que a professora elaborava. E, no panorama de prosseguir com as atividades iniciadas no ensino presencial, esse mesmo plano foi mantido através da implementação das atividades remotas. Como o assunto food aparece em todos os livros do $1^{\circ}$ ao $5^{\circ}$ ano do ensino fundamental I, embora seja disponibilizado em unidades e ordens distintas, este foi o tópico escolhido para ser explorado neste relato de experiência, pois possibilita pensar como o ILF pode ser trabalhado com alunos de diferentes idades (entre 6 e 10 anos) e etapas de ensino, sob a ótica de um único tema.

\section{Montando as aulas no Mazk buscando estimular um processo de ensino-aprendizagem ILF-aware}

A análise realizada diante dos objetos de conhecimento presentes nos livros adotados pelo município demonstra que os caminhos propostos pelos materiais não aparentam seguir uma perspectiva de ILF. No entanto, isso não significa que eles não possam ser utilizados dentro dessa perspectiva, haja vista que essa adequação é um movimento que depende mais da posição do professor para com a língua e da sua concepção de língua, do que se o instrumento está ou não 
LIMA, Jane Helen Gomes de; SAVIO, Gislane; ROSSO, Graziela Pavei Peruch. Inglês como Língua Franca (ILF) e o ensino-aprendizagem de língua inglesa em tempos de ensino remoto: um relato de caso aplicado ao ensino fundamental I

realmente elaborado para essa linha de pensamento. Nesse viés, a professora deste componente curricular passou a fazer adaptações dos conhecimentos de cada unidade, respeitando os tópicos, vocabulários, gramática e participação de seus alunos em cada uma de suas salas no Mazk, já que ela tinha objetivos bem definidos dentro de cada unidade do livro. E, seguindo a crença de Duboc (2012) de que é possível agir nas brechas, a docente procurou incorporar práticas que acreditava estarem alinhadas a um processo de ensino-aprendizagem mais ILF-aware, ou seja, práticas mais conscientes do conhecimento produzido pelas pesquisas em ILF (EL KADRI; GIMENEZ, 2013; GIMENEZ et al., 2015; JENKINS, 2012, 2015; JORDÃO, 2014; JORDÃO; MARQUES, 2018; SIFAKIS; TSANTILA; 2019).

O relato, portanto, busca estabelecer uma aproximação de como a educadora em questão intencionou trabalhar o global e o local da língua (SIQUEIRA, 2018) nas aulas elaboradas na plataforma Mazk por meio do tópico food. Para isso, foram selecionadas para análise e discussão duas salas virtuais já disponibilizadas para os alunos do $3^{\circ}$ ano do ensino fundamental I neste ambiente virtual. Pontuamos que o recorte efetuado para as duas salas do $3^{\circ}$ ano se justifica por possibilitar que os códigos das salas sejam compartilhados, no entanto, pontua-se que o mesmo tópico foi trabalhado com todas as turmas de $1^{\circ}$ ao $5^{\circ}$ ano, mantendo-se, dessa forma, o mesmo tópico e perspectiva de trabalho mais ILF-aware com todas as turmas.

A primeira sala sobre food, de código PNFW4SD8, teve por objetivo introduzir o vocabulário relativo às comidas próximas do cotidiano das crianças para que elas pudessem falar brevemente sobre um prato de seu gosto. Para explorar o tema da aula e oportunizar o contato dos alunos com a língua inglesa, a educadora disponibilizou uma série composta por quatro vídeos. No vídeo inicial, o "Chef Mumu", um boizinho falante da língua portuguesa, apresentou em inglês vocabulários como arroz, feijão e carne, ou seja, comidas presentes no cotidiano dos brasileiros. Já o segundo vídeo trouxe palavras referentes às frutas e teve como modelo de orador um falante de inglês da variedade dita padrão. Dando continuidade, as quatro refeições em inglês (breakfast, lunch, dinner e snack) foram introduzidas por escrito e, posteriormente, estudadas em um terceiro vídeo, que tinha como modelo de falante de inglês um brasileiro adulto. O quarto vídeo, que completa a sequência de inputs deste tópico, abordou foods and drinks por meio de adultos falantes do que parece ser, novamente, uma variedade de inglês dita padrão. Depois desta série de vídeos, foi indicada uma prática de vocabulário por meio de um jogo e, por fim, houve o desafio da semana.

Disponibilizada ao fim de cada aula como atividade opcional, a prática denominada desafio da semana foi elaborada pela professora como um recurso direcionado para que as crianças pudessem exercitar os tópicos aprendidos, bem como para oportunizar uma maior prática da língua 
LIMA, Jane Helen Gomes de; SAVIO, Gislane; ROSSO, Graziela Pavei Peruch. Inglês como Língua Franca (ILF) e o ensino-aprendizagem de língua inglesa em tempos de ensino remoto: um relato de caso aplicado ao ensino fundamental I

falada, visando assim o desenvolvimento da oralidade. No desafio proposto para a sala sobre comidas do cotidiano, a docente pediu que os alunos escolhessem uma refeição e desenhassem um prato contendo as foods mais usualmente ingeridas. Concluído o desenho, as crianças foram provocadas a gravar um áudio ou um vídeo descrevendo as comidas presentes em sua ilustração. As devolutivas das produções elaboradas pelos alunos foram encaminhadas pelo Whats App para a docente e, conforme desejo, compartilhadas pelas próprias famílias no grupo do Facebook da escola.

A segunda sala sobre food, de código Y27NS3M6, teve por objetivo retomar os vocabulários explorados na sala anterior e avançar, classificando as comidas em saudáveis e não saudáveis. Para isso, foram retomados alguns vídeos — do chef Mumu, de foods and drinks e das refeições - e, em seguida, foi disponibilizada uma explicação sucinta sobre os termos bealthy e unhealthy food, acompanhada de duas imagens: a primeira, contendo uma atividade de enumerar os nomes das bealthy foods nas gravuras corretas; e a segunda, ilustrando algumas junk foods na forma de um pictionary. Depois disso, foi realizada a descrição da estrutura would like com uma pequena explicação, expondo essa organização gramatical de modo implícito e demonstrando a funcionalidade dessa estrutura em ofertar certas comidas.

Para enriquecer a exposição, foram disponibilizados dois vídeos enfatizando o uso do would like, que tinham por modelos falantes adultos do que aparenta ser ingleses ${ }^{8}$ (CANAGARAJAH, 2007) do dito padrão. O primeiro praticava a oferta de diferentes foods e respostas curtas de aceite ou recusa (Yes, please! / No, thank you!), enquanto o segundo apresentava uma forma mais elaborada de informar o que se gostaria de comer (I would like to eat...). Por fim, foi proposto para os alunos, como desafio da semana, que eles gravassem um áudio ou um vídeo simulando um curto diálogo, que foi colocado por escrito para que completassem da forma que achassem mais indicado ( $A$ : What would you like to eat? / B: I would like some...). Completando a explicação do desafio da semana, a professora disponibilizou um último vídeo, de crianças (de uma escola bilíngue, falantes de espanhol como L1 de variantes distintas) falando inglês: ofertando, perguntando, aceitando e recusando comida, ou seja, praticando tudo o que foi aprendido até o momento. Vale ressaltar que para facilitar a compreensão das etapas desenvolvidas durante a aula, a professora gravou um vídeo de abertura, explicando como estavam organizadas as atividades desta sala e convidando os alunos a participarem do desafio da semana. 
LIMA, Jane Helen Gomes de; SAVIO, Gislane; ROSSO, Graziela Pavei Peruch. Inglês como Língua Franca (ILF) e o ensino-aprendizagem de língua inglesa em tempos de ensino remoto: um relato de caso aplicado ao ensino fundamental I

\section{Analisando o processo de ensino-aprendizagem ILF-aware a partir da prática}

Quando o assunto é a inclusão e a prática do ILF no processo de ensino-aprendizagem da língua inglesa, pesquisas de referência realizadas por autores brasileiros (EL KADRI; GIMENEZ, 2013; GIMENEZ et al., 2015; SIQUEIRA, 2018) apontam que ainda parecemos estar relativamente distantes de alcançar um consenso a respeito das implicações pedagógicas que um processo de ensino-aprendizagem ILF-aware pode exercer diante de seu público-alvo. Nesse sentido, torna-se mister ampliar as discussões acerca das possibilidades metodológicas para que essa concepção seja efetivada — não apenas na objetividade das aulas presenciais, mas quando de sua adaptação para o ensino remoto. Igualmente, oportunizar aos educadores (e simpatizantes da área) a reflexão por meio da prática permite identificar como esse ensino pode ser materializado e os resultados que podem ser alcançados a partir desse modo de se pensar, ensinar e aprender a língua inglesa no contexto da educação básica.

A descrição das duas salas apresentadas por este relato permite realizar algumas provocações relativas à maneira pela qual a educadora conduziu esse processo. Notam-se as ferramentas utilizadas com o propósito de descentralizar o modelo do falante nativo, em uma compreensão de que descentralizar ou alterar o foco não significa excluir ou apagar o padrão nativo, mas apresentar aos aprendentes o tipo de inglês padrão como mais um inglês que faz parte dos diferentes ingleses. Retornando à tentativa de descentralização do modelo do falante nativo mencionado anteriormente, percebe-se que essa não é uma tarefa fácil pois ainda há a presença de um número maior de vídeos com falantes do inglês dito nativo ao longo das aulas devido à dificuldade de se encontrar na internet outros materiais já produzidos e adequados ao tema desejado e ao público-alvo. Essa limitação impossibilitou que a professora oferecesse aos seus alunos uma ampla diversidade de ingleses por meio dos vídeos. Por fim, foram contemplados apenas alguns tipos de ingleses que se encaixam nos modelos ditos padrão, bem como opções de falantes de inglês advindos de outras poucas nacionalidades. Esse exemplo pode ser identificado na sala sobre o tema alimentos saudáveis e não saudáveis, na qual a educadora apresentou um material audiovisual tendo como modelo de falantes de inglês crianças cuja L1 é o espanhol. Além deste, ela também utilizou vídeos com falantes de inglês que tem como L1 o português brasileiro, bem como apresentou a si mesma como modelo de falante de inglês em vídeo pessoal gravado e disponibilizado na plataforma aos alunos.

$\mathrm{Na}$ metodologia utilizada pela professora, a inserção dos diferentes tipos de inglesesprincipalmente em materiais nos quais crianças aparecem como sujeitos falantes — buscou, mais do que permitir aos alunos (e também às famílias) que se enxergassem como falantes legítimos da 
LIMA, Jane Helen Gomes de; SAVIO, Gislane; ROSSO, Graziela Pavei Peruch. Inglês como Língua Franca (ILF) e o ensino-aprendizagem de língua inglesa em tempos de ensino remoto: um relato de caso aplicado ao ensino fundamental I

língua, propiciar às crianças uma identificação com os próprios protagonistas do discurso. Essa preocupação em retirar o nativo de sua posição de prestígio, escolhendo expô-lo a vídeos com diferentes tipos de ingleses, com falantes de repertórios linguísticos variados e colocando todos eles como modelos legítimos deste idioma, está de acordo com as discussões feitas na literatura de ILF e, apesar de parecer um detalhe, entende-se que já representa uma postura mais ILF-aware.

Outro ponto a ser discutido é o embasamento para a realização das atividades via Whats $A p p$ e, principalmente, o compartilhamento dos desafios da semana na rede social da escola. Nessa iniciativa, a docente procurou centrar-se na competência comunicativa dos alunos e na inteligibilidade do inglês falado por eles, buscando tratar o idioma mais como uma prática social do que um sistema que precisa ter como foco a forma ou a acurácia gramatical. Assim, com o convite de compartilhar seus desafios da semana no Facebook da escola, a professora estimulou a prática oral dos estudantes e oportunizou a eles compartilhar com a comunidade escolar os avanços linguísticos e comunicativos que estavam tendo durante o momento de pandemia. Outrossim, o acesso da criança aos vídeos compartilhados pelos colegas serviu como instrumento motivacional àqueles que ainda não haviam se sentido à vontade para gravar suas práticas orais nos desafios propostos pela professora.

A análise das produções audiovisuais partilhadas pelas famílias na rede social da escola e o envolvimento das crianças nas atividades propostas permitem inferir que os resultados foram ao encontro dos objetivos estabelecidos pela educadora. Os alunos deixaram transparecer certo conforto na realização das tarefas, com alguns deles, inclusive, fazendo uso de recursos de edição para melhorar seus vídeos, o que demonstra que o interesse superou o simples cumprimento de uma obrigação. Identificou-se, igualmente, a participação de familiares na realização de vários dos desafios produzidos, principalmente os que incluíam algum tipo de diálogo. Há também vídeos que apresentam alunos produzindo atividades mais complexas do que as propostas, o que demonstra que algo estimulou seu interesse em se desafiar a experimentar o idioma de modo mais agentivo.

Observa-se, no entanto, que muitos responsáveis expressaram seu desconforto em socializar as atividades das crianças em uma rede social, optando por efetuar as devolutivas somente pelo Whats $A p p$, com o envio de áudio ou vídeo, como maneira de garantir a participação. O foco na oralidade também marca uma postura mais ILF-aware, já que o inglês é utilizado como meio de expressão das crianças. Por meio deste idioma, elas comunicaram suas comidas favoritas, apresentaram uma refeição que desenharam, ofertaram e aceitaram alimentos e, então, utilizaram o idioma para algo real e significativo, percebendo, essencialmente, seus usos no cotidiano (mesmo 
LIMA, Jane Helen Gomes de; SAVIO, Gislane; ROSSO, Graziela Pavei Peruch. Inglês como Língua Franca (ILF) e o ensino-aprendizagem de língua inglesa em tempos de ensino remoto: um relato de caso aplicado ao ensino fundamental I

que abordados para fins didáticos). Atividades como essas aproximam o inglês da realidade dos alunos, mostrando que eles também podem fazer uso da língua para se comunicar de maneira significativa e, principalmente, que não é algo tão distante do seu dia a dia.

Por fim, vale salientar um tópico que não pode ser observado nem pelas práticas das crianças nos áudios e vídeos realizados, nem pela descrição das salas no Mazk, mas que é percebido como de suma importância nesta discussão e se fez mais visível nesse momento de pandemia e ensino remoto, no qual os responsáveis estão acompanhando diretamente as atividades das crianças em casa: a questão do inglês ser ou não um conhecimento passível, talvez até de direito, de ser apropriado pelos alunos do ensino fundamental I no contexto de uma rede pública municipal de educação. No movimento de realização das aulas, notou-se que muitas famílias foram relutantes com o ensino de inglês para as crianças, principalmente nas turmas do $1^{\circ}$ ao $3^{\circ}$ ano. Acredita-se que essa postura por parte dos responsáveis se deva à pouca familiaridade existente com a língua, o que dificulta a tarefa de ajudar e acompanhar as crianças nas atividades de modo mais intenso. Diante das resistências encontradas, foi efetuado um trabalho colaborativo entre a professora e a gestão da escola, buscando desconstruir o aparente medo do inglês — um sentimento que aparentava ser mais dos responsáveis do que das próprias crianças.

Por meio do contato constante com o público em questão, trabalhou-se no sentido de confortá-los quanto às dificuldades, deixando claro que a intenção das aulas era a de oferecer aos alunos oportunidades de praticar o idioma, mostrando que o importante é que as crianças produzissem as atividades do jeito delas e que os responsáveis não precisavam se preocupar com perfeição, além de informar que a professora estava interessada na apropriação do inglês pelos estudantes no ritmo deles, da forma que eles fossem capazes de aprender, e que os responsáveis podiam fazer contato caso precisassem de qualquer auxílio, entre vários outros suportes emocionais e pedagógicos oferecidos.

É válido citar ainda que as falas que os responsáveis trouxeram para a educadora são discursos comuns que perpassam o trabalho do professor de inglês dado o estranhamento que a maioria dos estudantes tem para com a língua. Pondera-se que esses discursos representam questões enraizadas sobre o ownership do inglês, que são enfrentamentos que estudos em ILF se propõem a fazer. O trabalho de incentivar os responsáveis a motivarem as crianças a participarem das atividades produzindo os desafios da semana para serem enviados via Whats $A p p$ ou publicados no grupo do Facebook da escola, teve como pressuposto um processo de ensino-aprendizagem mais ILF-aware e que procura indicar que nossas crianças podem ser falantes desta língua e que o inglês pode sim fazer parte do repertório linguístico delas. 
LIMA, Jane Helen Gomes de; SAVIO, Gislane; ROSSO, Graziela Pavei Peruch. Inglês como Língua Franca (ILF) e o ensino-aprendizagem de língua inglesa em tempos de ensino remoto: um relato de caso aplicado ao ensino fundamental I

\section{Considerações finais}

Este relato de experiência procura agregar para as discussões acerca de como as pesquisas em Inglês como Língua Franca (ILF) podem ser operacionalizadas nas escolas de ensino fundamental I, discorrendo sobre as práticas de ensino-aprendizagem de língua inglesa oferecidas em duas salas virtuais da plataforma Mazk disponibilizadas a um grupo de alunos de $3^{\circ}$ ano da rede municipal de Forquilhinha/SC.

A necessidade de compartilhar as práticas realizadas nas aulas de inglês durante o ensino remoto ocorre porque, apesar de todas as dificuldades que o momento impõe, é possível identificar os benefícios que o ensino através da plataforma Mazk proporciona, principalmente diante da oportunidade de acompanhar os alunos (e suas famílias) de maneira mais individualizada. Percebese que em uma sala com média de 25 alunos, com apenas uma aula de inglês semanal, talvez os resultados quanto ao desenvolvimento linguístico sejam inferiores se for trabalhado apenas o modelo presencial, dado que o ensino através do Mazk permite que o suporte seja efetuado de forma personalizada para cada criança, considerando sua dificuldades e o próprio ritmo de aprendizagem. Então, pensar em adotar um sistema híbrido para as aulas de língua inglesa em contraturno quando houver o retorno às aulas presenciais no "novo normal" aparece como uma possibilidade de ajudar os alunos a desenvolverem suas competências linguísticas e se perceberem como futuros falantes de inglês.

Reconhecemos que as tecnologias possibilitaram que as práticas descritas aqui se tornassem possíveis. Assim, as que estão neste relato são casos de sucesso, porém, nem todos os alunos da rede municipal se encaixam nesta categoria bem-sucedida, pois ainda existem estudantes sem acesso à internet, celulares, laptops ou tablets. Isso sem esquecer daqueles que enfrentam dificuldades para além da língua inglesa ou do uso das tecnologias. No entanto, isso não desconfigura o potencial que este relato tem. Desse modo, esperamos ter conseguido exemplificar como pode ser possível construir junto com os alunos práticas de ensino-aprendizagem mais ILFaware. 


\section{Dialogia}

LIMA, Jane Helen Gomes de; SAVIO, Gislane; ROSSO, Graziela Pavei Peruch. Inglês como Língua Franca (ILF) e o ensino-aprendizagem de língua inglesa em tempos de ensino remoto: um relato de caso aplicado ao ensino fundamental I

2 O habitus pedagógico refere-se à "matriz de percepções, de apreciações e de ações” que atua como guia e orienta tanto a reprodução de condutas como a invenção de novas estratégias de ensinar no dia a dia dos professores em ação (TEIVE, 2008, p. 31).

$2[\ldots]$ conceptualize, construct explanations for, and respond to the social interactions and shared meanings that exist within and among teachers, students, parents, and administrators, both inside and outside the classroom (original).

3 A professora em questão, responsável pela elaboração das aulas analisadas e também colaboradora deste relato, é funcionária efetiva na Rede Municipal de Educação de Forquilhinha desde o mês de fevereiro de 2020.

${ }^{4}$ Mazk é uma plataforma gratuita e pública. Ela está disponível no endereço <https://mazk.labtec.ufsc.br/ >.

${ }^{5}$ Com o intuito de proporcionar às escolas da rede um maior acesso às tecnologias, a Secretaria Municipal de Educação adquiriu, no ano de 2018, gabinetes móveis contendo 30 tablets e um notebook para cada Escola de Educação Básica - Anos Iniciais (EEBs). Mesmo tendo esses equipamentos a seu serviço, observou-se que eles eram pouco utilizados pelos professores, existindo ainda a necessidade de colocar à disposição deles possibilidades para seu uso no processo de ensino-aprendizagem. A plataforma Mazk aparece, portanto, como uma dessas alternativas.

${ }^{6}$ A proposta curricular de Forquilhinha passou por modificações em 2019/2020 para se adequar às exigências da BNCC, tendo sido finalizada ainda no primeiro semestre do corrente ano.

${ }^{7}$ Cabe ressaltar que, no início de 2020, a Secretaria de Educação convocou para uma reunião todos os professores de inglês da rede, em um movimento de apresentar o texto já elaborado sobre o componente inglês na Proposta Curricular Municipal. O objetivo desse encontro foi incluir esses educadores no processo colaborativo de construção do documento no que tange ao componente curricular em discussão.

8 Tomamos aqui o termo ingleses (Englishes) como forma de reforçar que mesmo dentro de uma mesma nacionalidade que tenha o inglês como sua L1, esse inglês não será homogêneo, sendo assim, existem diversos ingleses no mundo e até mesmo dentro de uma mesma nação.

\section{Referências}

$3^{\circ}$ ANO vídeo atividades. [S.I.:s.n.], 2020. 1 vídeo (ca. 6 min). Publicado pelo canal Jane Helen Lima. Disponível em: https://www.youtube.com/watch?v=0MRTEWL42Jk. Acesso em: 22 set. 2020.

ALIMENTOS e bebidas em Inglês (Foods and drinks in English). [S.I.:s.n.], 2018. 1 vídeo (ca. 10 min). Publicado pelo canal Baby Nenes. Disponível em:

https://www.youtube.com/watch?v=qh-H7c1VSgw. Acesso em: 20 set. 2020.

BRASIL. Parâmetros Curriculares Nacionais - terceiro e quarto ciclos: Língua Estrangeira. Brasília: MECSEF, 1998.

BRASIL. Base Nacional Comum Curricular: Educação Infantil e Ensino Fundamental. Brasília: MEC/Secretaria de Educação Básica, 2017.

CANAGARAJAH, Suresh. Lingua Franca English, Multilingual Communities, and Language Acquisition. The Modern Language Journal, v. 91, 2007.

COMIDA em inglês - Alimentos em inglês. [S.I.:s.n.], 2019. 1 vídeo (3:18 min). Publicado pelo canal Amigo Mumu. Disponível em: https://www.youtube.com/watch?v=Zf3nNd-lqI4. Acesso em: 20 set. 2020.

CURTO JÚNIOR, Renato; SANSON, Josiane; GUIMARÃES, Anna. Brincando com o Inglês: ensino fundamental. 3. ed. São Paulo: Editora do Brasil, 2016.

DUBOC, Ana Paula. Atitude Curricular: Letramentos Críticos nas Brechas da Formação de Professores de Inglês. 2012. 258 f. Tese (Doutorado em Letras) - Universidade de São Paulo, São Paulo, 2012. 


\section{Dialogia}

LIMA, Jane Helen Gomes de; SAVIO, Gislane; ROSSO, Graziela Pavei Peruch. Inglês como Língua Franca (ILF) e o ensino-aprendizagem de língua inglesa em tempos de ensino remoto: um relato de caso aplicado ao ensino fundamental I

EL KADRI, Michele; GIMENEZ, Telma. Formando professores de inglês para o contexto do inglês como língua franca. Acta Scientiarum. Language and Culture, v. 35, n. 2, p. 125-133, 2013.

ENGLISH flash games for learning vocabulary. Food game. Disponível em: https://englishflashgames.blogspot.com/2008/09/food-game.html. Acesso em: 20 set. 2020.

FOOD - Fast food 2 Using the grammatica structure I would like to eat. [S.I.:s.n.], 2020. 1 vídeo (1 min). Publicado pelo canal Listen to Reading. Disponível em:

https://www.youtube.com/watch?v=YINPajndoAQ. Acesso em: 21 set. 2020.

FORQUILHINHA, Secretaria Municipal de Educação. Proposta Curricular da Rede Municipal de Ensino de Forquilhinha, 313 p., no prelo, 2020.

FRUTAS em Inglês para crianças (Fruits in English). [S.I.:s.n.], 2017. 1 vídeo (ca. 7 min). Publicado pelo canal Baby Nenes. Disponível em: https://www.youtube.com/watch?v=OBP23lxgEE. Acesso em: 20 set. 2020.

GIMENEZ, Telma; EL KADRI, Michele, CALVO, Luciana; SIQUEIRA, Sávio; PORFIRIO, Lucielen. Inglês como Língua Franca: desenvolvimentos recentes. RBLA, v. 15, n. 3, p. 593-619, 2015.

JOHNSON, Karen. Understanding language teaching: Reasoning in Action. Canada: Heinle \& Heinle, 1999.

JENKINS, Jennifer. English as a Lingua Franca from the classroom to the classroom. ELT Journal, v. 66, n. 4, p. 486-494, 2012.

JENKINS, Jennifer. Repositioning English and multilingualism in English as a Lingua Franca. Englishes in Practice, v. 2, n. 3, p. 49-85, 2015.

JORDÃO, Clarissa Menezes. ILA-ILF-ILE-ILG: Quem dá conta? RBL $A$, v. 14, n. 1, p. 13-40, 2014.

JORDÃO, Clarissa; MARQUES, Anderson. English as a lingua franca and critical literacy in teacher education: shaking off some "good old" habits. GIMENEZ, T.; EL KADRI, M. S.; CALVO, L. C. S. (Ed.). English as lingua franca in teacher education: a Brazilian perspective. Berlin: De Gruyter Mouton, 2018, p. 53-68.

O QUE É O MAZK? Disponível em: https://mazk.labtec.ufsc.br/sobre. Acesso em 28 set. 2020.

REFEIÇÕES em Inglês - Meals | Iupi Inglês Criativo. [S.I.:s.n.], 2016. 1 vídeo (5:20 min). Publicado pelo canal Inglês Criativo. Disponível em: https://www.youtube.com/watch?v=nTQ13P3sOB8. Acesso em: 20 set. 2020.

SIFAKIS, Nicos; TSANTILA, Natasha. English as a Lingua Franca for EFL contexts. Bristol: Multilingual Matters, 2019.

SIQUEIRA, Domingos Sávio; SOUZA, Juliana. Inglês como Língua Franca e a esquizofrenia do professor. Estudos Linguísticos e Literários, n. 50, p. 31-64, 2014. 
LIMA, Jane Helen Gomes de; SAVIO, Gislane; ROSSO, Graziela Pavei Peruch. Inglês como Língua Franca (ILF) e o ensino-aprendizagem de língua inglesa em tempos de ensino remoto: um relato de caso aplicado ao ensino fundamental I

SIQUEIRA, Domingos Sávio. Inglês como Língua Franca não é uma zona neutra, é zona transcultural de poder: Por uma descolonização de concepções, práticas e atitudes. Revista Linguas \& Letras, v. 19, n. 44, p. 93-113, 2018.

TEIVE, G. M. Uma vez normalista, sempre normalista: cultura escolar e produção de um habitus pedagógico (Escola Normal Catarinense - 1911/1935). Florianópolis: Insular, 2008.

WHAT would you like? Learning English for Kids/Inglês para niños. [S.I:s.n.], 2018. 1 vídeo (4 min). Publicado pelo canal Albany School of English. Disponível em:

https://www.youtube.com/watch?v=fq7a6TT2PpE. Acesso em: 21 set. 2020.

WOULD you like some...? Food Vocabulary/English speaking practice/ESL/EFL/ELL. [S.I.:s.n.], 2017. 1 vídeo (ca. 5 min). Publicado pelo canal Mark Kulek. Disponível em: https://www.youtube.com/watch?v=HRtAgS6RIDA. Acesso em: 21 set. 2020.

Recebido em: 30 set. 2020/ Aprovado em: 01 dez. 2020

\section{Cite como}

\section{(ABNT NBR 6023:2018)}

LIMA, Jane Helen Gomes de; SAVIO, Gislane; ROSSO, Graziela Pavei Peruch. Inglês como Língua Franca (ILF) e o ensino-aprendizagem de língua inglesa em tempos de ensino remoto: um relato de caso aplicado ao ensino fundamental I. Dialogia, São Paulo, n. 36, p. 269-282, set./dez. 2020. Disponível em: https://doi.org/10.5585/dialogia.n36.18346.

\section{American Psychological Association (APA)}

Lima, J. H. G., Savio, G., \& Rosso, G. P. P. (2020, set./dez.). Inglês como Língua Franca (ILF) e o ensino-aprendizagem de língua inglesa em tempos de ensino remoto: um relato de caso aplicado ao ensino fundamental I. Dialogia, São Paulo, 36, p. 269-282.

https://doi.org/10.5585/dialogia.n36.18346. 